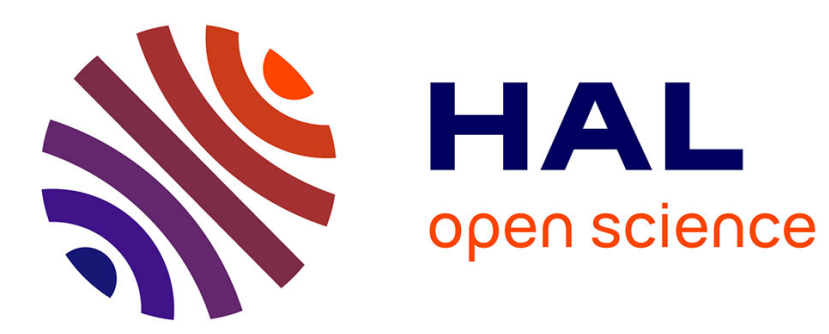

\title{
Accessible Comics for Visually Impaired People: Challenges and Opportunities
}

\author{
Frédéric Rayar
}

\section{To cite this version:}

Frédéric Rayar. Accessible Comics for Visually Impaired People: Challenges and Opportunities. The Second International Workshop on coMics ANalysis, Processing and Understanding, 2017, Kyoto, Japan. hal-01651358

\section{HAL Id: hal-01651358 https://hal.science/hal-01651358}

Submitted on 29 Nov 2017

HAL is a multi-disciplinary open access archive for the deposit and dissemination of scientific research documents, whether they are published or not. The documents may come from teaching and research institutions in France or abroad, or from public or private research centers.
L'archive ouverte pluridisciplinaire HAL, est destinée au dépôt et à la diffusion de documents scientifiques de niveau recherche, publiés ou non, émanant des établissements d'enseignement et de recherche français ou étrangers, des laboratoires publics ou privés. 


\title{
Accessible Comics for Visually Impaired People: Challenges and Opportunities
}

\author{
Frédéric Rayar \\ Laboratoire d'Informatique, Université de Tours \\ Tours, France \\ frederic.rayar@univ-tours.fr
}

\begin{abstract}
Over the recent years, techniques from Document Images Analysis have brought new insights into the understanding of comics. This paper outlines the challenges and opportunities of conceiving accessible comics for visually impaired people. After an overview of the existing initiatives, we briefly highlight in what extent the Document community could help to achieve such a goal in a multidisciplinary way, by collaborating with fields such as Human-Computer Interactions, Cognitive Science and even Education Research.
\end{abstract}

\section{INTRODUCTION}

\section{A. Visually Impaired People}

Visual impairment is a severe reduction in vision that cannot be corrected with standard solutions such as glasses or contact lenses. Lacking a "normal" vision, visually impaired (VI) people are either "blind" (complete absence of vision) or have a so-called "low vision" (moderate or severe visual impairment). This disability reduces one's capacity to perform daily activities such as walking, reading and socialising.

According to the World Health Organization (WHO) [1], in 2010 there were globally 285 million VI people, of whom 39 million were blind. The WHO estimated that $80 \%$ of all vision impairment can be prevented or cured, and is currently driving a global action plan (2014-2019) regarding universal eye health for the prevention of blindness and visual impairment [2]. However, it remains that many VI people face a lifetime of inequality, as they often have to face barriers to education, information and culture.

To address this issue, a range of mediums and tools have been proposed to allow one VI person to access information or to learn, depending on the severity of sight loss and the age when this loss occurred. Among others, we can mention: (i) the Braille tactile reading and writing system, (ii) enlarged print or (iii) audio transcription. It is worth noting that none of the aforementioned solutions makes consensus. For instance, not all VI people can access information through the medium of Braille, simply because they did not learnt it.

\section{B. VI people access to illustrated books}

One can easily wonder about the interest of making illustrated books (hence images) accessible to VI people. We argue as follows: first, VI people are surrounded by books since they are young, irrespective of when the loss of their sight occurred. Books surround them, either at home, at school and even at friend places. Unfortunately, only a small subset of these books are made available to them, by taking into account their impairment.

Second, books in general are an important medium to help the growth of children. At first, pictorial books are used to assist the learning of children, and allow them to have a "mental image" associated to a letter or a word (spoken or written). With this experience, it is then natural to use illustrated books, where images and words act together to form a meaningful story. The images enhance the story by either describing a particular character or a scene, allowing one to have a "mental animation" of the story they read. Later, it also helps adults when they learn a new script or language. For instance, the learning of Japanese hiragana, katakana and kanji, or the latin script alphabet.

Last, books are a good way to access, discuss and share with non visually impaired people. It can bring another vector that allows VI people to be included and to socialise.

\section{Comics}

Among illustrated books, we focus on comics. Indeed, comics are a substantial part of the culture in several countries such as Japan, France, Belgium and USA. They have became an important medium since nowadays, comics are spread all over the world.

On top of that, comics represent an important market worldwide. Let us take the example of Japan: the market in Japan in 2016 was about 4.45 billion USD. It is worth mentioning that this market sees an evolution of consumption of its users: in February, 2017 a report [3] from the All Japan Magazine and Book Publisher's and Editor's Association attested that the sales of printed manga saw a 9.3\% decrease while those of digital manga saw a $27.5 \%$ increase compared to 2015 numbers.

This phenomenon has brought the Document Image Analysis (DIA) research community an opportunity in the last decade to use their techniques to improve comics' analysis, processing and understanding. 


\section{Motivation}

Almost ten years ago, in 2007, an initiative [4] by a small Japanese association, namely the Illustrated Braille Club, made a small coverage in the comics' news networks. The members of this association were manually producing accessible comic books (a few mangas and Disney storybooks) for VI people. They were not only providing a Japanese- or English-to-Braille transcriptions of the texts, but also recasting the illustrations into impressionistic raised dots. According to the club's 82-year-old representative Kouji Sangawa, "the visually impaired don't have many opportunities to experience art, so they enjoy our work."

By looking at this initiative, its seems natural to think that the DIA community, especially the works on comics' analysis, processing and understanding, could contribute to such an effort in an enhanced and more automated way.

In this paper, we present the first academic work, to the best of our knowledge, that aims at making comics accessible to VI people (both blind and persons with low vision). This paper has three goals:

1) to present some existing initiatives that have been done to make images and illustrated books accessible to VI people, along with the existing means and tools that can be used to do so,

2) to see in what extent the previous works done by the DIA community in the last decade (e.g. the eBDtheque project [5], or the Manga109 project [6]) could be exploited and enhanced,

3) to open a discussion with experts in comics' understanding during the MANPU workshop and bringing new perspectives to the field by considering the accessibility property.

The paper is organised as follows: first, we present in Section II a survey of the existing initiatives regarding the accessibility of images and comics for VI people. Then, in Section III, we present some challenges and opportunities of creating accessible comics, not only for the DIA community, but also for related fields such as Human-Computer Interactions (HCI), Cognitive Science (CS) and even Education Research (ER). Finally, we conclude in Section IV and give some perspectives.

\section{RELATED WORKS}

\section{A. Accessible images for VI people}

According to the early works of Yvonne Eriksson [7], one of the first tactile images dates back to the $19^{t h}$ century. In the book "A Peep Into the menagerie of Birds" (1841), the image of a falcon was printed in relief, using the technique of embossed paper. The page also contained the description of the bird in Roman characters in relief. Such tactile images were used to teach VI people in specialised institutions. In the case of the falcon, it was related to natural science education.

In this study, we focus our attention on making images accessible to VI people, not from the point of view of education, but rather the accessibility to culture. However, accessing information through illustrated books could also be an indirect way of learning.

From a technical standpoint, the major solutions that have been used to allow a VI person to access images are:

1) audio description,

2) printed Braille description,

3) printed tactile pictures (in relief),

4) combination of the above solutions.

From an academic standpoint, a few academic works can be found in the literature regarding the means of making images accessible to VI people. We categorise them below, according to their research field.

\section{1) Art and Design:}

In their works, Art and Design researchers study the concepts that designers have to take into account during the conception of tactile images or accessible illustrated books.

During her PhD thesis in 1998 [7], Yvonne Eriksson took the historical point of view, and made an exhaustive inventory of the tactile pictures that have been made for the blinds in the period from 1784 to 1940 .

Olivier Poncier, an author/illustrator also developed a research project on tactile images. In his work [8], that started back in 1981, he used Braille along with tactile images, and aimed at providing graphic representations while focusing on the reality and the narration for tactile reading. His work led to several illustrated books "Eyes at your finger-tips" published by Chardon Bleu publishers.

Danielle Valente [9] took the semiotic point of view to produce guidelines, in order to conceive accessible books for VI children. Taking into account possible understanding conflicts that may arise for VI children when they interact with tactile images, one outcome of her work was the design of a game, namely "Tactilonary", in partnership with the association "Les Doigts Qui Rêvent" [10].

\section{2) Cognitive Science and Education Research:}

From the cognitive perspective, several studies have been conducted since almost 20 years on the perception of tactile images by sighted and VI people. The focus was set on: $(i)$ how a VI child was exploring the tactile image and (ii) the impact of the tactile image properties on children's haptic acuity.

More recently, in 2013, a user evaluation [11] has been conducted to see to what extent the illustration technique impacts the tactile images recognition by early blind children. They concluded that textured pictures was the illustration technique that was best grasped by early blind children.

In 2015, the PhD work of Oriana Orlandi [12] also aimed at understanding how VI children were processing the images 
in relief, in tactile books specially designed for them. In her conclusions, she proposed guidelines for the conception of tactile illustrated books, but also for the educational methods to teach VI children to grasp the haptic interaction.

\section{3) Image Analysis:}

More related to the DIA field, we have found only one series of works [13], [14] and [15], at the best of our knowledge, that proposed to use Image Processing and Pattern Recognition techniques for the automatic transcription of images for VI people. The authors focused their study on the transcription of educational images (e.g. geographical maps, histograms, etc.). The pipeline they have proposed consists of: first a text/graphic separation is performed using the Stroke Width Transform method [16]. The extracted text areas are fed to the Tesseract OCR system and then converted into Braille. Second, depending on the type of the image they are converting, they either seek for some shape primitives (arrows, circles, etc.) or segment the images based on colours and assign a specific tactile texture.

\section{B. Accessible comics for VI people}

In this section, we present some examples of existing initiatives to make comics accessible to VI people, categorised according to the technical solutions they employ.

\section{1) Using audio:}

In 2004, GraphicAudio [17] started to propose audio book versions of US comics. The audio editions mainly feature the reading of the comic script. In 2007, they proposed famous DC Comics works such as "Infinite Crisis" or "Justice League of America”.

In 2011, Marvel Comics proposed one of their comic, namely Daredevil (that stars a blind hero), to the blind demographic. To do so, they offer the audio edition for free [18]: the script of the comic was read, along with the panels' descriptions. Following this initiative, GraphicAudio started to release licenses of Marvel Comics, such as "X-Men", "Iron Man" or "Guardians of the Galaxy".

A more recent initiative is Comic Empowered [19], an online comic book store for VI people. They sell their own comics' audio book versions or the ones produced by other companies such as GraphicAudio. The major difference is that their website has been designed for VI people and is completely accessible for them, using a high-contrast display or a screen reader.

\section{2) Using Braille:}

In order to produce braille version of a comic, a process of recasting is performed, namely the novelisation of the comic. For instance, in 2004, the Belgian Braille League manually novelised a volume of the comic "Alix - Le Sortilège de Khorsabad”. They presented the unique 2-volume Braille version of the comic [20] in a public event.

Another alternative has been proposed in 2014: "Sensus. El Universo en sus ojos", the first Mexican Braille comic book.
On the behalf of the Nacional Monte de Piedad of Mexico, this comic was created for a charity operation: for each comic that has been bought, a pair of glasses was donated to a visually impaired child in need. The comic presented is a version for both sighted people and VI people. On one side of the book, the illustrations narrate the story while on the other side, Braille text described the story and the dialogues.

3) Using tactile images:

Several illustration techniques can be used to produce tactile images:

- Raised lines: they are produced using swell paper. Here, the objects' contours are highlighted. However, it requires the VI people to perform a contour-following exploration.

- Thermoforming: they are produced using plastic sheets and a thermoforming machine. The objects' contours are highlighted along with the area within, which can be felt in $3 \mathrm{D}$.

- Textured images: they are obtained either by assembling several textures (fabrics, foams, paper, etc.) or by adding a texture code to each areas of the objects (striped lines, dots, etc.).

Figures 1, 2 and 3 present the tactile images obtained using the three aforementioned illustration techniques. Only a few one-time experiments have use these techniques to produce comics accessible to VI people.

\section{4) Using digital images:}

In 2008, Christophe Ponsard et al. [21] proposed to use screens to allow persons with low-vision or motor-impairment to read comics. More specifically, they implemented a digital comics' viewer, namely eComics, where a special attention was given to the comics' navigation and magnification. To do so, they performed an automatic panel segmentation using the watershed technique [22], followed by the panels' ordering. Later, an improvement has been proposed [23] to perform bubble text automatic text recognition, using Java OCR [24].

\section{5) Using combinations:}

In order to access the information through several channels, combination of the above techniques have been proposed:

- Audio + Braille: for instance, the publisher Delcourt propose the "Nuit Blanche" collection [25], comics that consist of the Braille edition, along with a USB drive. The USB drive contains the dialogues and each panel description.

- Tactile images + Braille: for instance, the works mentioned in Section I that are produced by the Japanese association, namely the Illustrated Braille Club [4].

\section{6) Others:}

Other attempts have been proposed by illustrators and designers:

- Philipp Meyer designed "Life" [26], a tactile comic for blind people. In this comic, each page has 4 frames high- 
lighted by raised dots. The story is simplified and involves two characters that are represented by two textured disks.

- In 2016, Ilan Manouach conceived "Shapereader" [27], a tactile and textured constructed language. It materialises in a collection of wooden engraved tablets that can be used to construct images and narrative tactile artwork.

\section{Summary}

During this last decade, several works have been proposed to make images, illustrated books and comics accessible to VI people. Several observations, conclusions and guidelines came out of these works, and should be taken into account in the future studies. However, actual comics are still rare in the education or the culture access of VI children and adults. Several issues have been raised such as: their cost, the time to build one single comic independently of the technical solutions used, but also the usefulness and the effectiveness of such tactile mediums.

In this paper, we argue that the combination of several research fields' expertise can help to conceive accessible comics for VI people. The outcomes of such a project could be: (i) less expensive if we select less content to be printed, or by proposing a dedicated new HCI tool, (ii) less timeconsuming to produce, by using semi-automated methods, (iii) useful by allowing access to an important part of the culture, and by providing new interactions for VI people. However, regarding the effectiveness, we cannot get ahead of ourselves and must conduct user evaluation with the targeted audience.

\section{Challenges And Opportunities}

Since it appears that a multidisciplinary collaboration is needed to provide relevant accessible comics for VI people, we pinpoint here some scientific and technological challenges that may be overcome thanks to the expertise of different research communities. This list of challenges is not exhaustive and an open discussion during the MANPU workshop will help to refine and enhance it.

\section{A. For the DIA community}

\section{1) Comics' understanding and indexing:}

Following the eBDtheque project [5] and the Manga109 project [6], we currently have two publicly available data sets of comics' collection. The indexing that has been done on these data sets, by extracting Element of Content (EoC) such as panels, speech balloons, text lines, etc. could be directly used as a starting point to make them accessible to VI people. Furthermore, we could enhance these comics' understanding by extracting other information that could be useful for both sighted and VI people, such as onomatopoeia, panel mood, motion in panel, etc.

\section{2) Drawings' simplification:}

Processing images such as the ones in Figure 2 may not seem challenging because only a few strokes appear, and match perfectly the shapes of the objects in the panels.
However, one can easily see the challenges that recent comics bring, where the panels are more detailed, enhanced with a lot of strokes to texture and give either the impression of motion of a character, or a kind of ambiance to a panel. To address this challenge, techniques such as EoC spotting, background removal and drawings' simplification [28], could be used and adapted to our use case.

\section{3) Real-time image processing methods:}

It seems natural to think that fully automated methods will not be adequate to conceive VI accessible comics. Indeed, experts must be able to "correct" the recast image proposed by the system, in order to make it relevant for the tactile exploration of VI people. Hence, a semi-automated approach seems relevant. To cope with this constraint, real-time image processing and EoC extraction must be provided. This joins the recent thinkings of the community to conceive real-time and responsive DIA systems to process (textual) information "in the wild".

\section{B. For the HCI community}

\section{1) Novel tactile surfaces:}

Making comics accessible to VI people could create new tactile surfaces. On the one hand, we wonder about the usage of $3 \mathrm{D}$ printers to produce tactile images and comics. This could reduce drastically the cost of producing accessible images. However, the usability and impact on the haptic acuity remains to be studied.

On the other hand, to match with the digitalisation trend of comic, it would be relevant to see in what extent haptic screens could be used for both sighted and VI people. Dedicated systems could be conceived with concept of "raising pixels" or electrovibration [29]. Such initiatives can be already be found in academics [29] and in business [30].

\section{2) Novel comics' interactions:}

Following the evolution of consumption of comics' readers, the enhancement of the comics' understanding and indexing would allow to conceive new multimodal interactions. Targeting both sighted and VI people, one major challenge will be the alignment of the multimodal information, namely visual, haptic and audio.

\section{For the CS and the ER communities}

\section{1) Mental image study:}

Making accessible comics could help to understand more the process of mental image for VI children and adults. Since a story is told, this could help to investigates questions such as the continuity of the mental image of a character through the story or the positioning of objects and characters in the mental scene.

\section{2) Exploration study:}

The haptic exploration of a "complexly" laid out page of a comics will be interesting to investigates. Furthermore, for VI people, more information (reading direction, panel 
orientation, characters names) shall be convey at the beginning to help the readers. How this information shall be presented and made easily searchable to VI people is a critical point.

\section{3) Pedagogical guidelines:}

Since new means and tools will be provided to access comics, the learning process of VI people, and especially children, will have to be studied. This will help to propose guidelines on how to teach and accompany the learning and use of these new interactions. Since several cultures will be involved (French, Japanese, American), it would also be interesting to study the influence of the culture on educational methods.

\section{Conclusions And Perspectives}

In this paper, we have presented the challenges and opportunities to conceive accessible comics for the VI people. This objective is engaging for the DIA community: it takes advantage of the previous works done in comics' understanding while providing interesting new perspectives. However, it appears mandatory that a multidisciplinary approach must be adopted, involving HCI, CS and ER communities.

Following discussions during the MANPU workshop, the straightforward perspectives of this study are: (i) to build and strengthen a network of experts including academics, associations and comics providers, (ii) write a research project proposal and (iii) begin the first experimentations.

\section{ACKNOWLEDGMENTS}

The author would like to thank the first anonymous reviewer for his relevant references, that contributed to improve the final version of the paper.

\section{REFERENCES}

[1] D. Pascolini and S. P. Mariotti, "Global estimates of visual impairment: 2010," British Journal of Ophthalmology, vol. 96, no. 5, pp. 614-618, 2012.

[2] W. H. Organization, "Prevention of blindness and visual impairment," http://www.who.int/blindness/en/, 2017, [Online; accessed 31July-2017].

[3] A. J. Magazine, B. Publisher's, and E. Association, "Report on printed and digital comics' market," http://www.ajpea.or.jp/book/21702/index.html, 2017, [Online; accessed 31-July-2017].

[4] A. N. Network, "Japanese volunteers transcribe manga for blind people," http://www.animenewsnetwork.com/news/2007-07-24/japanesevolunteers-transcribe-manga-for-blind-people, 2007, [Online; accessed 31-July-2017].

[5] C. Guérin, C. Rigaud, A. Mercier, F. Ammar-Boudjelal, K. Bertet, A. Bouju, J.-C. Burie, G. Louis, J.-M. Ogier, and A. Revel, "ebdtheque: a representative database of comics," in Proceedings of the 12th International Conference on Document Analysis and Recognition (ICDAR), 2013, pp. 1145-1149.

[6] A. Fujimoto, T. Ogawa, K. Yamamoto, Y. Matsui, T. Yamasaki, and K. Aizawa, "Manga109 dataset and creation of metadata," in Proceedings of the 1st International Workshop on coMics ANalysis, Processing and Understanding. ACM, 2016, pp. 2:1-2:5.

[7] Y. Eriksson, Tactile pictures :pictorial representations for the blind, 1784-1940, ser. Gothenburg studies in art and architecture. Acta Universitatis Gothoburgensis, 1998, vol. 4.

[8] O. Poncer, "Image tactile : de la figuration pour les aveugles," in Handicap and Communication. Médiation Et Information (MEI), 2013, pp. $167-180$.
[9] D. Valente, "Dessin et cécité : étude de la communication graphique des jeunes non-voyants," Ph.D. dissertation, Université Paris 1, 2012.

[10] "Les doigts qui rêvent," http://www.ldqr.org/, [Online; accessed 31-July2017].

[11] A. Theurel, A. Witt, P. Claudet, Y. Hatwell, and E. Gentaz, "Tactile picture recognition by early blind children: the effect of illustration technique," vol. 19, no. 3, 2013, pp. 233-240.

[12] O. Orlandi, "La compréhension des images tactiles chez les enfants porteurs d'un handicap visuel," Ph.D. dissertation, Université de Bourgogne, 2015.

[13] Y. Chen, Z. Haddad, and J. López-Krahe, "Contribution to the automation of the tactile images transcription process," in Computers Helping People with Special Needs - 14th International Conference, ICCHP 2014, Paris, France, July 9-11, 2014, Proceedings, Part I, 2014, pp. 642-649.

[14] Z. Haddad, Y. Chen, and J. López-Krahe, "A pattern recognition approach to make accessible the geographic images for blind and visually impaired," in 2015 IEEE International Conference on Image Processing, ICIP 2015, Quebec City, QC, Canada, September 27-30, 2015, 2015, pp. 3205-3209.

[15] Z. Haddad, Y. Chen, and J. L. Krahe, Image Processing and Pattern Recognition Tools for the Automatic Image Transcription. Springer International Publishing, 2016, pp. 197-203.

[16] B. Epshtein, E. Ofek, and Y. Wexler, "Stroke width transform." IEEE, January 2010

[17] “Graphic audio," http://www.graphicaudiointernational.net, [Online; accessed 31-July-2017]

[18] "Marvel comics - daredevil 1 - audio book," http://marvel.com/files/podcasts/DAREDEVIL_1_edited.mp3, 2011, [Online; accessed 31-July-2017]

[19] "Comic empowered," http://comicsempower.com/, [Online; accessed 31 July-2017].

[20] "Alix - le le sortilège de khorsabad," http://bibliotheque.braille.be/fr/catalogue/litterature/romans/romanshistoriques-biographiques/700164-le-sortilege-de-khorsabad, 2004, [Online; accessed 31-July-2017].

[21] C. Ponsard and V. Fries, "An accessible viewer for digital comic books," in Computers Helping People with Special Needs, 11th International Conference, ICCHP 2008, Linz, Austria, July 9-11, 2008. Proceedings, 2008, pp. 569-577.

[22] S. Beucher and F. Meyer, "The morphological approach to segmentation: the watershed transformation," in Mathematical Morphology in Image Processing, E. Dougherty, Ed., 1993, ch. 12, pp. 433-481.

[23] C. Ponsard, R. Ramdoyal, and D. Dziamski, "An ocr-enabled digital comic books viewer," in Computers Helping People with Special Needs - 13th International Conference, ICCHP 2012, Linz, Austria, July 11-13, 2012, Proceedings, Part I, 2012, pp. 471-478.

[24] R. Cemer, "Java ocr," http://roncemer.com/software-development/javaocr/, 2011, [Online; accessed 22-August-2017].

[25] "Delcourt's "nuit blanche" collection for the blinds," https://www.bdgest.com/news-603-BD-delcourt-invente-la-bd-pournon-voyants.html, 2011, [Online; accessed 31-July-2017].

[26] P. Meyer, "Life," http://www.hallo.pm/life/, 2013, [Online; accessed 31July-2017].

[27] I. Manouach, "Shapereader," http://shapereader.org/, 2016, [Online; accessed 31-July-2017].

[28] X. Liu, T.-T. Wong, and P.-A. Heng, "Closure-aware sketch simplification," ACM Trans. Graph., vol. 34, no. 6, pp. 168:1-168:10, Oct. 2015.

[29] O. Bau, I. Poupyrev, A. Israr, and C. Harrison, "Teslatouch: Electrovibration for touch surfaces," in Proceedings of the 23Nd Annual ACM Symposium on User Interface Software and Technology. ACM, 2010 pp. 283-292.

[30] "Blitab," http://blitab.com/, 2017, [Online; accessed 31-July-2017].

[31] "The little prince," https://www.blog.thelittleprince.com/little-prince-inbraille/, 2014, [Online; accessed 31-July-2017].

[32] "Gaston lagaffe," http://www.lavillebraille.fr/des-livres-a-voir-et-atoucher/, 2004, [Online; accessed 31-July-2017].

[33] "Lucky luke," https://accessibibabf.wordpress.com/2014/10/31/uncoffret-multi-sensoriel-sur-la-bande-dessinee-concu-par-et-pour-lesenfants-non-voyants/, 2014, [Online; accessed 31-July-2017]. 


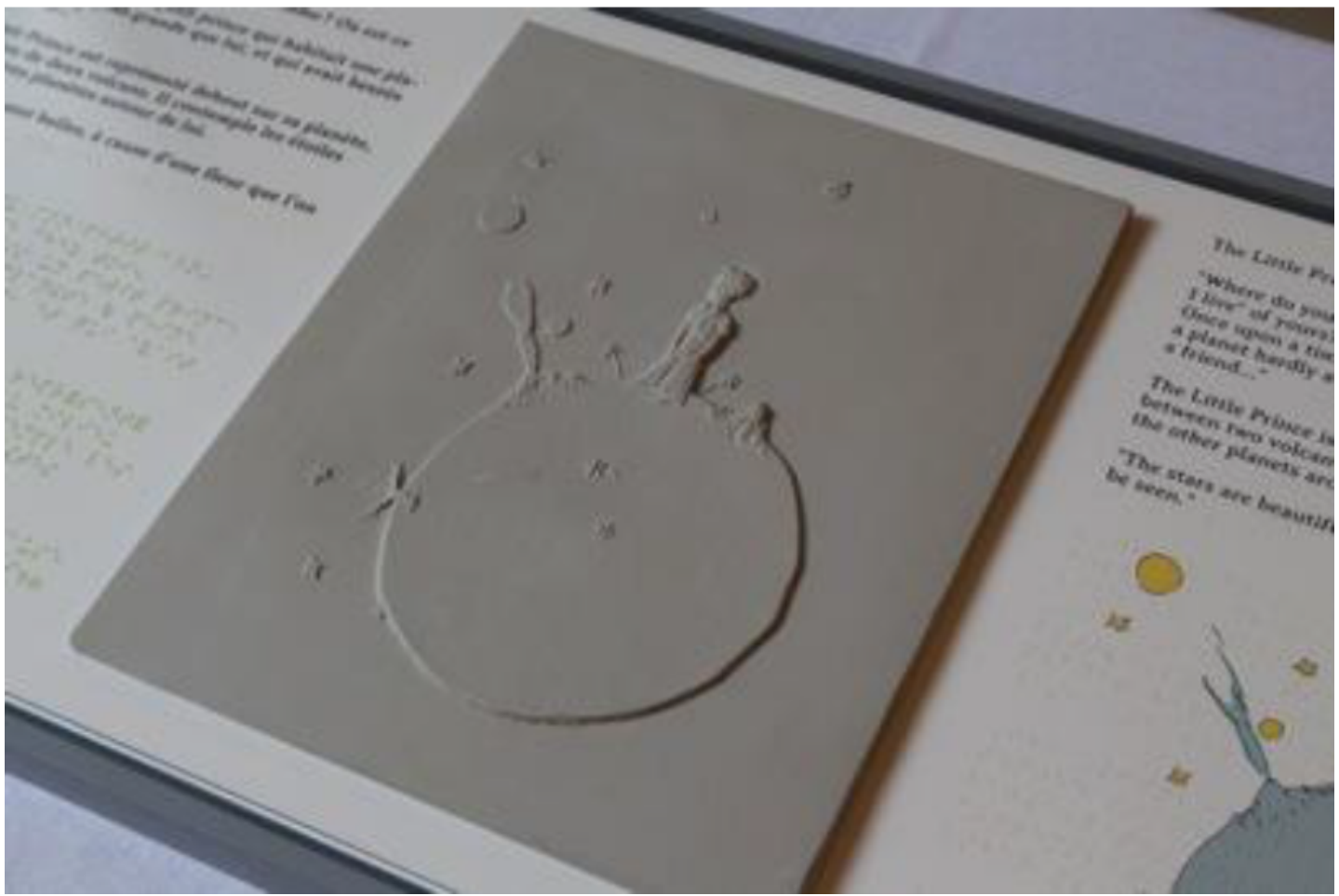

Fig. 1. Tactile image produced using the thermoforming illustration technique. "The Little Prince" of Antoine de Saint-Exupéry. Illustration from [31]

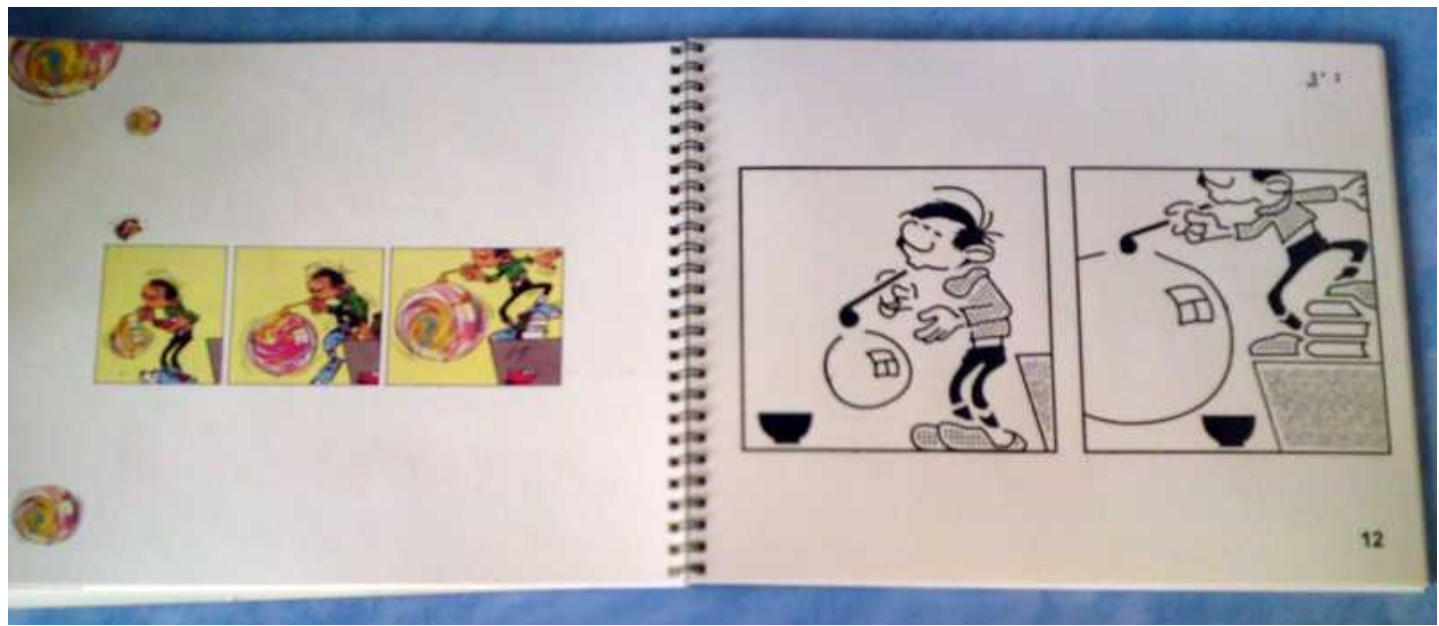

Fig. 2. Tactile image produced using the raised lines illustration technique. "Gaston" of André Franquin. Illustration from [32]

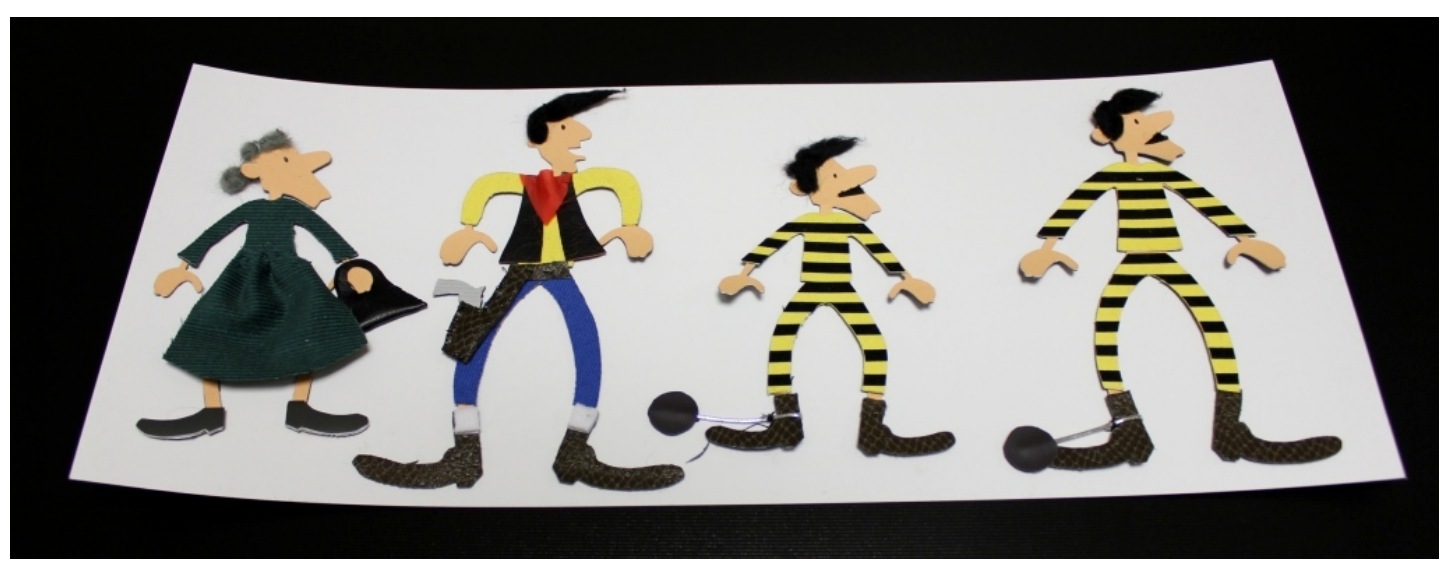

Fig. 3. Tactile image produced using the textures illustration technique. "Lucky Luke” of Morris and Goscinny. Illustration from [33] 